\title{
Fostering Entrepreneurial Mindset and Innovation in a Cross-Listed Science and Engineering Course
}

\section{Dr. Bahram Roughani, Loyola University Maryland}

Professor of Physics and Associate Dean for the Natural and Applied Sciences at Loyola University Maryland. Experimental condensed matter physicist with emphasis on optical spectroscopy and Electron Microscopy of electronic materials. PI on the NSF-IUSE supported collaborative project, "The PIPLINE Project", a national effort in collaboration with American Physical Society (APS) aiming at enhancing Physics Innovation and Entrepreneurship (PIE) education. 


\title{
Fostering Entrepreneurial Mindset and Innovation in a Cross-Listed Science and Engineering Course
}

\begin{abstract}
:
Greater attention to promoting entrepreneurial mindset and innovation among STEM disciplines in recent years enhances the potential role for science and engineering majors as changemakers. The efforts by the emerging and growing Physics Innovation and Entrepreneurship (PIE) community in recent years bear resemblance to and overlaps with the efforts of engineering educators in terms of cultivating entrepreneurial mindset among college students. Physics Innovation and Entrepreneurship (PIE) efforts at Loyola University Maryland is shaped by the launch of two NSF funded initiatives; the Pathways to Innovation in 2015 and the PIPELINE Network; an NSF collaborative research grant in 2016. One of the outcomes of these efforts is a new course on Technical Innovation and Entrepreneurship, a cross listed course by Physics, Computer Science, and engineering. In this course students are introduced to innovation and entrepreneurial mindset through "User Innovation" concept, which is the focus of this report. Physics, computer science, and engineering students, as well as those majoring in communication, business, chemistry, biology, and psychology often take this as an elective course.

The "User Innovation" module introduces Innovation and Entrepreneurship (I\&E) concepts in context of students' passion and their personal experience instead of using textbook definitions. Students are engaged in active learning practices that guides them through a journey, starting with "User Innovation" module and ending with a team project. In this process students identify needs, pains, and issues they care about, and concluding with a prototype developed through a team project that represent solutions to student defined problems. Teams project members collaboratively work on the necessary steps for launching a startup based on the team project "product". They develop and submit a team project portfolio that document the challenges they faced, and their progress and achievements, while documenting how their prototype was treated to "launch a startup". The success of the team project is measured by the quality of the prototype created, ability to adhere to a project timeline, quality of the written project report and documentations, the oral presentation, and the team project portfolio. Future plans include leveraging concept map to assess the impact of the whole course as well as the "User Innovation" module on students' perception and attitudes about entrepreneurial mindset.
\end{abstract}

Acknowledgement: Support for this work is provided by the National Science Foundation's IUSE program under Award No. 1624882 
Introduction:

Preparing STEM students for the knowledge economy requires combining technical and theoretical knowledge with the 21 st-century skills. These have typically been defined as communication, collaboration, critical thinking and creativity, but "the skills for working in a complex and connected world" (Trilling and Fadel, 2012, p. 47) are in fact broader, and fall into the areas of (1) learning and innovation (critical thinking, problem solving, creativity and innovation); (2) digital literacy (information, media and technology literacy); and (3) life and career skills (initiative and self-direction, leadership, adaptability, and accountability) [1]. Helping undergraduates to acquire these skills involves application of knowledge as opposed to rote memorization, teamwork as opposed to individual tasks, and awareness about social and human needs in addition to having technical know-how (i.e., a sociotechnical rather than technocentric approach)

STEM disciplines such as Engineering and Computer Science that prepare undergraduates to enter the job market, have led efforts in integrating entrepreneurial thinking into their curriculum. This approach can be of interest to other STEM disciplines, because combining technical skillset and entrepreneurial mindset provides career opportunities for all majors when they are participating in the knowledge economy. The report on; "Cultivating Diversity Champions: Practices and Lessons from Two NSF Geoscience Opportunities for Leadership In Diversity (GOLD) Projects", suggests that; "One key challenge was the widespread belief among geoscience faculty that "science is science", and that the question of who gets to practice geoscience is answered using the scientific method." [2] This may reflect a technocentric mindset that may be a prevailing attitude in other areas of basic sciences, especially when the role of science and scientists is exclusively viewed in context of search for truth about matters and energy and discoveries about natural phenomena. This approach pays little or no attention to unearthing the truth about the connection between scientific knowledge and the impact of scientific discoveries on human life. However, a sociotechnical perspective offers an alternative approach by connecting technical skills with social impact, as described by Leydens and Lucena [3]. Our motivation for introducing "user innovation" is in part to provide an example for implementing a science and engineering course based on a sociotechnical approach. Therefore, we have developed a cross listed science and engineering course that allows students be engaged in activities that highlight the connection between technical skills and know-how and entrepreneurial mindset.

Integrating entrepreneurial thinking within STEM curriculum not only can enhance the $21^{\text {st }}$ century skills, but also it has positive impact on students' perception about their technical field of study. For example, Ryan Kelly, and Susan Yoon [4] have studied the impact of the integrating STEM and Entrepreneurship or STEEM (i.e., Science, Technology, Engineering, Entrepreneurship and Mathematics) on high school girls. Their study suggests that Teachers' promotion of active learning, hands-on activities and critical thinking, and their active promotion of STEEM careers appear to have increased the girls' engagement in STEEM, and possibly to have reinforced the idea that they might pursue STEEM careers, while the introduction of Entrepreneurship is helping Girls' Interest in STEEM. During the teacher interviews, 11 out of the $13(85 \%)$, stated explicitly that entrepreneurship was having a positive impact on the 
students. From the teachers' perspectives, all students appeared interested in entrepreneurship. They also stated that; "the girls who participated in this study were clear that they connect with STEEM and see career opportunities in STEM through the inclusion of entrepreneurship."

Similar efforts at the college level has proven to be of strong interest to minority students such as the HBCU Innovation Summit program [5]. Also, the study by Sheffield et.al., shows positive impact of combining STEM and entrepreneurship on minority students' interest in STEM based on the report on Lessons Learned from the STEM Entrepreneurship Academy [6]. Therefore, combining entrepreneurial thinking and STEM education may impact all students. However, the impact might be even greater for the underrepresented minority students by empowering them for success in the knowledge economy based on their 21 st century skillset and entrepreneurial mindset.

\section{Background:}

Three major initiatives in recent years have shaped the efforts related to Physics Innovation and Entrepreneurship (PIE) at Loyola University Maryland. First, the findings by the Joint Task Force on Undergraduate Physics Programs (J-TUPP), convened by the American Physical Society (APS) and the American Association of Physics Teachers (AAPT) to investigate the question, "What skills and knowledge should the next generation of undergraduate physics degree holders possess to be well prepared for a diverse set of careers?" This NSF-funded research (IUSE award \#1540570) resulted in a seminal report, "Phys21: Preparing Physics Students for 21st Century Careers," [7] which concluded that, while the majority of physics graduates go on to become successful contributors to the US STEM workforce, their preparation for all manner of career paths would have been vastly improved if undergraduate physics programs emphasized translatable, 21st-century skills such as working in teams, writing, programming, applying physics to solve interdisciplinary problems, designing and developing products, managing complex projects, and working with clients. This is an important factor considering approximately $95 \%$ of physics graduates go on to careers in the private sector or government labs, yet most undergraduate physics programs prepare students primarily for academic careers. In fact, a survey of 1,407 mid-career physics $\mathrm{PhD}$ recipients found that they frequently attributed career success to their skills and abilities outside of physics (e.g., interpersonal, problem solving, computing, and analysis skills). Conversely, some of the most frequently mentioned career barriers among 1,321 respondents included lack of interpersonal and business skills (Porter, 2019). [8]

The second factor was the Pathways to Innovation that was launched at Loyola University Maryland in 2015, the year prior to the Phys21 report. Pathways to Innovation initiative was created through an NSF supported program and coordinated through Epicenter at Stanford University in collaboration with VentureWell. We implemented this initiative based on agile change management or "Strategic Doing" approach, leading to curricular and co-curricular changes that has shaped the innovation ecosystem in our campus. Finally, in 2016, we implemented the PIPELINE Network, a collaboration between American Physical Society (APS) and six universities, including Loyola University Maryland (IUSE Award \# 1624882). The PIPELINE Network aimed at creating and documenting new approaches to teaching innovation and entrepreneurship in physics, developing research instruments to investigate the link between 
physics innovation and entrepreneurship (PIE) education experiences and corresponding student and faculty attitudes. The goals of the PIPELINE Network were to (1) deliver tested PIE curriculum to a wider cohort of practitioners; (2) assess of effects of PIE implementation on student and faculty attitudes towards innovation and entrepreneurship, and discover barriers to PIE implementation; and (3) build a community of expert practitioners who can mentor other institutions. One of the specific outcomes on these effort under the PIPELINE Network was the development and launch of a course on Technical Innovation and Entrepreneurship, which starts with a module on "User Innovation", as described below.

User Innovation Module:

The module in User Innovation has been developed based on the original work by Eric Von Hippel [9-14], a set of videos showing case studies related user innovation and lead users [15], and his book on Dementalizing Innovation [16]. Eric von Hippel describes the process of usercentered innovation and shows how it can benefit both users and manufacturers. He discusses how the emergence of user-centered innovation may bring changes in business models and in public policy. The impact of user innovation is expanding because of the unique opportunities provided to users through knowledge economy. Users, leveraging the improvements in computer and communications technology, are increasingly empowered to be engaged in new products and services. Moreover, innovating users often freely share their innovations and engage in collaborative creation, that has led to the emergence of user-innovation communities. Eric von Hippel describes the emerging system of user-centered innovation and the reasons for users developing new products and services for themselves. He also describes when and why it pays users to reveal their innovations for the use of others. Example of democratizing innovation and collaborative creation can be the open-source software movement, but it is not limited to software only. For example, he discusses cases of surgical equipment, surfboards, and development of scientific instruments, in addition to software security. He discusses the significant role of lead users in product and service development, because they are ahead on marketplace trends, thus their innovations are often commercially attractive. Von Hippel discusses the benefit to manufacturers in seeking out innovations developed by users as an approach to boost their business. For example, the custom semiconductor industry has engaged in collaborating with user-innovators by providing them with toolkits for developing new products.

Some of the well-known user innovators success stories include; GoPro, Dropbox, Airbnb, and Khan academy. However, the role of user innovation is not confined to software or consumer products and services. For example, knowledge economy has led to the advent of citizen science activities, enabling participation by individuals with different level of skills and education to engage in the collaborative creation process. This includes the work of David Land, a maker who become the cofounder and CEO of OpenROV by teaching himself to become an amateur oceanographer. In a TED talk in 2013, he described how he and a network of ocean lovers teamed up to build open-sourced, low-cost underwater drones to conduct their ocean exploration [17]. Organizations such as Citizen Science Association [18], and Scistarter.org [19] are leveraging crowdsourcing to engage individuals in scientific discoveries. Even government agencies have recognized the impact of citizen science in accelerating innovation through public 
participation based on crowdsourcing such the efforts by Citizenscience.gov [20]. Moreover, scientists in general, and physicists in particular have traditionally been user innovators, even if that is not the term being used to refer to them. For example, Riggs and von Hippel (1994) conducted a case study on incentives to innovate by user innovators when they focused on scientific instruments. They have shown that many of the scientific instruments originally were developed by scientists trying to address a specific science related need that had no commercially available solution at the time, thus as user innovators they created new science instruments [13].

The background presented here provided the motivation to develop a module on User Innovation. We designed this module to engage students in activities as described below that involves identifying needs based on personal interest, defining problem, formulating solutions, and implement their plan. This process also includes self-assessment and peer-assessment activities. An abbreviated version of the instruction provided to students to guide them through various steps of user innovation activities is presented below.

Step1 - What's the problem (Top 10 Pains):

The first step of User Innovation module deals with needs recognition. Students are asked to make a list of at least ten problems that they have faced in life, or problems that they care about or issues they have passion for. These are problems that are specific, occur frequently, are painful, and currently do not have adequate solutions. The guideline is that students should write about any issues impacting their life that may be associated with school, work, hobbies, family, personal health, financial matters, technology, or other issues they care about or have passion for. The goal here is for students to develop the ability to clearly identify and concisely communicate problems that are specific.

Step 2 - Self-Assessment of Top 10 Pains:

Conducting a self-assessment of the "top 10 pains" is done using a rubric to help students enhance their skills in defining problems, because according to Charles Kettering; "A problem well stated, is a problem half-sold". They consider the breadth and specificity of the answers they have provided. The goal here is to evaluate the quality of the ideas proposed and develop a habit for providing productive feedback. Moreover, students are asked to rate the quality of their original ideas only as an opportunity for self-reflection, however, self-rating scores are not used in the course grade calculations.

Step 3 - Top 3 Pains:

Dealing with ten problems at a time is not manageable, thus, students are asked to review the original list of top ten problems and select the top three issues that they care about the most. The idea is to avoid lumping the ten problems into three general problem areas, but to choose three discrete problems from their existing list of ten problems. The aim is to set priorities by narrowing down the choices of problems to solve.

Step 4 - Self-assessment of top three pains:

A self-assessment of assignment 3 (Top 3 pains) is conducted in this step. The emphasis here is on assessing depth, method, and specificity. A self-assessment rubric provides guidance on how thorough they were in defining and selecting the three problems they have selected. This 
includes attention to how specific they were in their selection, or whether they have analyzed factors such as level of painfulness, and whether the problems are described with a good level of specificity.

Step 5 - Selecting a problem to solve that matches your skills:

This is an introspective exercise asking students to review their skills and understand how their skills enable them as a problem solver. One of the lessons here is to realize a good way to keep an innovation cost low is to utilize the skills that they already have. Students are asked to think about the things they like to do, their experiences, knowledge, core competencies, hobbies, professional skills, or special insights they have developed based on their unique life experiences when listing their skills. This will help students think through the process when deciding on one problem to solve, which include:

- Conducting assessment of the skills that they have. Also, this may highlight the skills they may easily add based on the skills they already have, such as an adjacent or aspirational skill. For example, if a student knows one programing language, then it is easier to learn another language as compared to starting programming from scratch. Similarly, one may apply a skill to solve a problem in a different filed. For example, many physicists and engineers with strong analytical and programing skill have become prolific Data Scientists, while applying their skills to solve problems in various domains outside their academic training such as health or business.

- Choose one problem from the existing list of three problems that may best match their skills.

- Frame the problem. This means explore how one could solve own problem by utilizing their own skills and frame the problem to fit their skills.

Step 6 - Self-Assessment:

In this step student conduct self-assessment, however, they are not provided a rubric to guide them through the self-assessment process. For this step, students are asked to first develop a self-assessment rubric that can be implemented in assessing the work done in Step 5 exercise. To do this, students draw from the experience they gained through rubric provided to them to conduct self-assessment exercises in step-two and step-four. Students are asked to think how they would assess their work in view of the desired breadth, focus, and framing needed for this assignment according to the guideline provided. This provides the opportunity for students to engage in reflection, discernment and metacognition. They conduct a self-assessment of the work they completed in step-five based on the rubric they have created.

\section{Step 7 - Who shares your pain:}

To discover whether the problem identified by students is shared by others, they explore who else might have the same problem. The goal is to identify whether the problem identified addresses a broader need that is shared by others. To achieve this, students are asked to conduct interviews as a tool for market discovery for their ideas or engage in other effective approaches such as observation or need discovery methods. To accomplish this, students are asked to brainstorm about groups of people that might share their problem and Identify at least 3 such groups or segments. 


\section{Step 8 - Conducting Interviews:}

Students choose 1 group of people or segment from the few that they have already identified. To understand who may care about the same problem, they are asked to conduct interviews, while being in an inquiry mode to explore whether the problem might be shared by others. This is a fact-finding exercise, and not looking for confirmation of the original idea. Analysis of the results of the interviews help determining how to procced. Students are asked to include the questions and lessons learned during interviews in the User Innovation portfolio. This may lead to (often does) changes in both problem definition and suggested solution(s).

Step 9 - Co-forming the problem:

A fuller description of the innovation idea and plan is created in this step. This involves implementing a system for re-evaluating the innovation plan according to the new knowledge gained, thus co-forming the problem and solution using their skills. This comprise of:

- Students write down the problem that they had set out to solve initially. Then they state the problem just as they had in the beginning of the process. Next, they restate the problem based on what they have learned so far, in particular using the feedback received and lessons learned through interviews.

- Next, students are asked to write down their solution concept as they had initially imagined it. This is followed by restating their solution concept as they see at that time based on the feedbacks received. They are asked to reflect on changes they see, what works or doesn't about their initial solution concept, and has it expanded, shifted focus, or got completely redefined, and other insights they might have developed about their idea.

- Students also are asked to assume their idea leads to launching a "product". if so, how do they imagine it being shared with others.

Step 10 - Idea Pitch and Team Formation:

Every student is given 90 seconds to concisely pitch their idea to the rest of the class to communicate their idea succinctly and to convince others to select the idea presented for a team project to work on, which means other students to give up their own ideas to join the idea presented.

The team formation process includes:

- Displaying the title of each idea and the name of the students who pitched the idea on a board or a visible area in class.

- Each student can vote three times to support their favorite idea(s).

- Project selection: Student votes identifies the most popular ideas that can potentially become a team project.

- Team Formation: Students select the project they like to work on based on the following considerations:

$\circ$ The idea they are most passionate about

$\circ$ The idea that matches their skills the best 
$\circ$ The best team to join considering diversity of the team and the match between the skillset of the team members and the skills needed to complete the project.

- The project that is both interesting and doable within the semester timeframe

- The number of members in each team that ideally is 3 , but not more than 4 .

- Team Re-Organization Process: Each team is asked to review skills needed to complete the project and compare that with the skill set of team members. Students will be given the opportunity during a limited time (no more than a week) after the original team formation to exchange team members, if necessary, based on how well the skills of the original team members matches the skills needed to complete the project successfully.

- Project Plan: Each team will develop a project plan, with timeline, milestones, and deliverables that they have to adhere to. This will be reviewed on a weekly basis should there be the need for any revisions and adjustments.

Step 11 - Innovation Diffusion:

Students make choices among all options available in how to share their innovation. In this exercise, they will assume that they are choosing to diffuse their team project innovation in order to enable them to complete the rest of the Technical innovation and Entrepreneurship course activities. The project team members may consider for example one of the following options:

- Peer-to-Peer diffusion. If so, they are asked to describe important factors to consider that can increase the chances of this innovation to be adopted

- Market Diffusion, or both market and peer-to-peer. If so, they are asked to explain the reasons behind the decision.

- Decide whether to license the innovation or to produce it as a team?

- Ultimately, students are asked to explain how they plan to move ahead to implement their ideas and achieve the goals set for the diffusion of their innovation.

- Peer Assessment: Peer Assessment is an opportunity for students to give and receive feedback based on analysis of the proposed plan for diffusing innovation by their classmates. A rubric guiding this peer-assessment is provided to enhance the quality of the feedbacks. The rubric includes comment on whether the proposed plan answered the questions posed in the exercise.

Step 12 - User Innovation Reflections:

The final step of User innovation exercises is providing a reflection about this module addressing issues such as:

- The forces that are democratizing innovation,

- Why and how, do they democratize innovation, and

- The most relevant forces from the student point of view

Peer Assessment: The last step also includes a peer-assessment about their reflection about User innovation module activities as described earlier. 
Connection with the rest of the course: The set of exercise for the User Innovation module described are designed to be completed during the first three weeks of the semester. The formation of teams to work on team projects takes place during week four of the semester. Projects start during week five of the course, and it is used to practice the topics covered during the rest of the semester. This is designed to practice on how to launch a startup based on the team project idea. The final outcome is developing a prototype by each team counted as fifty percent of the course grade. This is assessed based on the quality of the final product, ability to adhere to a project timeline, project documentations and project portfolio, final report, and team presentation. Examples of team projects in this course are shown below. The idea for each and every project can be traced back to one of the ten ideas a student wrote during the very first week of the course that are:

- The Buzz-Band project: An Arduino based inexpensive alternative to "smart phones" providing solution to two problems; (1.) a roommate friendly silent alarm clock, and, (2) A device for those who need assistant to maintain focus during the day.

- The Seat-Seek project: A Raspberry Pi Microprocessor based sensor to find available seats in the library or other public spaces.

- The Sound-Pool project: An App allowing to play songs based on the vote by the audience rather than selected by the DJ

- The TeeCee Clamp project: a 3D printed prototype clamp allowing laptop and bags to hang directly off the side of the table, while providing quick access to the bag.

- The Civitas project: An App that connects local volunteers with volunteering opportunities.

- The Hale Packaging project: Provide consumers with an easy, fast, and affordable way to portion-control food at home or on the run.

- The Potium Application project: Centralized app for on-campus events, focused on student needs, awareness about campus opportunities, and engagement.

- The Meta project: A Magnetic Enhanced Travel Accessory (META), Designed as a pop socket for phones.

- The Blue Zone project: An App designed for the college students to contact campus police quickly in an emergency that is more effective than the blue light security system.

- The Guided Cuts project: A guidance system to assist Zamboni drivers making precision cuts while saving operation time.

Assessment:

The assessment of the Technical Innovation and Entrepreneurship, including the User Innovation module, so far has been limited to the end of the semester student course evaluations and comments. Recently, we added supplemental questions linked to the course learning objectives as part of the standard course evaluation questions. The supplemental questions and the feedback by students are shown in the following table. The aggregated percent of student answers indicating either "agree" or "strongly agree" for all questions to be greater than $98 \%$, while six of the eight questions show a response rate of $100 \%$ for either "agree" or "strongly agree". 


\begin{tabular}{|l|l|c|}
\hline \multicolumn{1}{|c|}{ How well this course prepared you to: } & $\begin{array}{c}\text { (Agree + Strongly } \\
\text { Agree) Percent }\end{array}$ \\
\hline 1 & Identify needs \& recognize technical venture opportunities. & $100 \%$ \\
\hline 2 & $\begin{array}{l}\text { Conduct a self-evaluation necessary for connecting one's skills with } \\
\text { entrepreneurial pursuit. }\end{array}$ & $100 \%$ \\
\hline 3 & $\begin{array}{l}\text { Demonstrate understanding about innovation process (including User } \\
\text { Innovation, technical, legal, and financial aspects associated with } \\
\text { Technical Ventures and Technical Startups). }\end{array}$ & $100 \%$ \\
\hline 4 & $\begin{array}{l}\text { Show an understanding about entrepreneurship, social entrepreneurship, } \\
\text { and intrapreneurship. }\end{array}$ & $100 \%$ \\
\hline 5 & $\begin{array}{l}\text { Conduct a patent search and examine and evaluate the quality of patents. } \\
\text { Analyze value proposition, including economic, cultural, and ethical } \\
6\end{array}$ & $\begin{array}{l}\text { Use effective and appropriate communication skills (including a written } \\
\text { term project report, oral presentation, and creation of entrepreneurial } \\
\text { elevator pitch). }\end{array}$ \\
\hline 8 & $\begin{array}{l}\text { Complete a successful technical team-based term project that include } \\
\text { ideation, opportunity recognition, innovation management, Business } \\
\text { Model Canvas (BMC), Intellectual Property (IP), startup strategies, } \\
\text { technical ventures creation, and commercialization plan. }\end{array}$ & $92 \%$ \\
\hline
\end{tabular}

The future assessment plan for this course will include using the concept map to examine the impact of this course on nurturing entrepreneurial mindset of students [21-25]. To achieve this, the concept map will be covered during the first week of the course, and students participating in the assessment will submit concept maps representing their perception about entrepreneurial mindset during the first week, after the completion of the User Innovation module, and during the last week of the semester. The correlation among three concept maps submitted by each student will be investigated to determine the impact of the course on students' perceptions regarding entrepreneurial mindset, and whether those have been positively impacted based on this course.

Summary:

Introduction of User innovation as the first module in a course on Technical Innovation and Entrepreneurship has been well received by students. The main advantage of this approach is allowing students learn about innovation and entrepreneurial thinking based on their passion and personal experience. By arriving at a solution through a semester long team project that is designed based on a student defined problem, they develop higher level of creative confidence. This can have positive impact on self-efficacy as a science or engineering major. Moreover, this approach allows having greater emphasis on sociotechnical approach by applying scientific knowledge and technical skills to address societal and human needs using entrepreneurial mindset. Our future efforts will further explore the impact of user innovation module and the whole course on students' perception of and understanding about entrepreneurial mindset using concept map approach. 
References:

1. Trilling, C. and Fadel, B. (2012), "21st Century Skills: Learning for Life in Our Times", Jossey-Bass (a Wiley Imprint) ISBN-13: 978-0470475386. https://www.amazon.com/21st-Century-Skills-Learning-Times/dp/0470475382

2. American Society for Engineering Education (ASEE) (2020). "Cultivating Diversity Champions: Practices and Lessons from Two NSF Geoscience Opportunities for Leadership in Diversity (GOLD) Projects. Washington, DC. https://www.asee.org/documents/publications/reports/2019-Cultivating-DiversityChampions-GOLD.pdf

3. Leydens, J.A., Lucena,J.C., Engineering Justice: Transforming Engineering Education and Practice, (2017), 978-1-118-75730-7, Wiley-IEEE Press. https://www.wiley.com/en$\underline{\text { us} / 9781118757307}$

4. Kelly, R. P (2017), “An Exploration of Stem, Entrepreneurship, and Impact on Girls in an Independent Day School”, University of Pennsylvania, ProQuest Dissertations Publishing, 2017. 10277920. https://search.proquest.com/docview/1912412041?pq-origsite=gscholar

5. HBCU Innovation Summit, https://uncf.org/programs/hbcu-innovation-summit Viewed January 31, 2020

6. Sheffield, A., Morgan, H. G., Blackmore, C (2018), "Lessons Learned from the STEM Entrepreneurship Academy", Journal of Higher Education Outreach and Engagement, Volume 22, Number 3, p. 185. https://openjournals.libs.uga.edu/jheoe/article/view/1406/1403

7. TUPP, (2016). "Phys21: Preparing Physics Students for 21 st-Century Careers", https://www.compadre.org/JTUPP/docs/J-Tupp_Report.pdf

8. Porter, A.M. (2019). "Physics PhDs Ten Years Later: Success Factors and Barriers in Career Paths", https://www.aip.org/statistics/reports/physics-phds-ten-years-later-success-factorsand-barriers-career-paths

9. Von Hippel, Eric (2009) "Democratizing Innovation: The Evolving Phenomenon of User Innovation,” International Journal of Innovation Science No. 1, Vol 1 pp. 29-40.

10. Von Hippel, Eric (2007) "Democratizing Innovation: The Evolving Phenomenon of User Innovation" Chapter 8 in Science, Technology and Innovation Indicators in a Changing World: Responding to Policy Needs, OECD, pp 125-138.

11. Lilien, Gary L., Pamela D. Morrison, Kathleen Searls, Mary Sonnack, Eric von Hippel, (2002) "Performance Assessment of the Lead User Idea Generation Process," Management Science, Vol 48, No 8 (August) pp. 1042-1059.

12. Von Hippel, Eric (2005) "The best way to innovate? Let lead users do it for you" Inc Magazine, September

13. Riggs, William and Eric von Hippel (1994), "The Impact of Scientific and Commercial Values on the Sources of Scientific Instrument Innovation," Research Policy 23 (July): 459469.

14. von Hippel, Eric (1976) "The Dominant Role of Users in the Scientific Instrument Innovation Process," Research Policy 5, no. 3 (July):212-39.

15. MIT Bootcamp videos, A Path to Entrepreneurship - video play list (October 30 2019): https://www.youtube.com/playlist?list=PLQykyC1zr8f8-ZqsNfXbPC05Ug71R2km- 
16. Von Hippel, Eric (2005) Democratizing Innovation, Cambridge, MA: MIT Press (April)

17. David Lang, My Underwater Robot, TED talk (2013) https://www.ted.com/talks/david_lang_my_underwater_robot

18. Citizen science: Home of Citizen Science Association (February 2, 2020), https://www.citizenscience.org/

19. Scistarter (February 2, 2020), https://scistarter.org

20. CitizenScience.gov, to accelerate the use of crowdsourcing and citizen science across the U.S. government (February 2, 2020), https://www.citizenscience.gov/\#

21. Martine, M.M., Mahoney, L.X., Sunbury, C.M., Schneider, J.A., Hixson, C., Bodnar C.A. (2019), "Concept Maps as an Assessment Tool for Evaluating Students' Perception of Entrepreneurial Mindset.” ASEE 2019 Annual Conference and Exposition, June 16-19, 2019. Tampa, Florida.

22. Watson, M.K., Barrella, E., and Pelkey, J. (2018). Assessment of Conceptual Knowledge using a Component-Based Concept Map Scoring Program. International Journal of Engineering Education, 34(3), 1025-1037.

23. Barrella, E., Henriques, J. Gipson, K. (2016). Using concept maps as a tool for assessment and continuous improvement of a first-year course. Proceedings of the 2016 ASEE Annual Conference \& Exposition, Atlanta, GA, June 26-29, 2016.

24. Ruiz-Primo, A., On the use of concept maps as an assessment tool in science: What we have learned so far. Revista Electrónica de Investigación Educativa, 2000. 2(1): p. 29-53.

25. Watson, M.K., et al., Assessing Conceptual Knowledge Using Three Concept Map Scoring Methods. Journal of Engineering Education, 2016. 105(1): p. 118-146. 